\title{
Determination of media and television literacy levels of sport consumers filtered out of the students of the school of Physical Education And Sports
}

\author{
Hakan UNAL \\ Mugla Sitki Koçman University, School of Physical Education and Sports, Mugla, Turkey.
}

Received 28 March, 2013; Accepted 11 July, 2014

\begin{abstract}
This study is aimed to determine the literacy levels of media and television and the level of addiction of sport consumers filtered out of the students of the School of Physical Education and Sports and to investigate the relationship between these two levels. Sport consumers studying in Mugla University, School of Physical Education and Sports constitute the study group. "Media and Television Literacy Level Scale" was used in the research. The level of internal consistency is found by researchers in order to determine the reliability of the scale. The reliability coefficient for the dimension of the literacy of the scale was .73 and the dimension of addiction was .75. The scale was applied by researchers to 409 sport consumers who study in the School of Physical Education and Sports of Mugla Sitki Kocman University by using face-to-face interview method. Data were evaluated by use of SPSS 19 software package program and interpreted in the form of tables. As a result, $39.9 \%$ of sport consumers were found to be literate, $49.6 \%$ to be high-level media and television literate and $10.5 \%$ were found to be medium-level media and television literate. According to this result, the media and television literacy levels of sport consumers can be said to be high. An inverse relationship was found for scores of literacy and addiction that was examined in the first two parts and the scores of media and television literacy levels. The average literacy level of sport consumers was at a high level and the level of addiction was found to be low.
\end{abstract}

Key words: Media literacy, television literacy, addiction, sport consumer, student.

\section{INTRODUCTION}

The large number of people who follow sports has created the inability to remain insensitive to mass media. Nowadays, sports news is featured as separate television programs and special sports programs are made and broadcasted live. The large number of people who are interested in sports has resulted in giving importance to sports-related television commercials (Unal, 2009). Media organizations can increase audience potential considerably by broadcasting specialized sports competitions live and the tendency of featuring these television programs increases. Credibility, attractiveness and power are required for an effective communication. These three

E-mail: hakan@mu.edu.tr. Tel: +02522113170-05057244432. Fax: +02522111933.

Author a gree that this a rtic le remain pemanently open access under the terms of the $\underline{\text { Creative Commons }}$ Attribution License 4.0 Intemational Lic ense 
characteristics of the source lead to changes in behaviors of recipients. These characteristics affect the behaviors of recipients as a result of three different characteristics of recipient psychology. Credibility is described with internalization, attractiveness with identification and power with compliance. Another factor affecting the credibility of the source is the information and experience that source has about the product and service advertised. A real bond has to exist between the people giving the message and product or service for the message to be credible (Terence, 1989; Gençer, 2001; Goknar, 2001). Every effort aimed at researching and examining dynamics of sports marketing components should reveal what marketing components are by considering the perspectives of consumers (Yalcin et al., 2004). Understanding profiles and behaviors of sport consumers is extremely important from the viewpoint of sports administrators and sports marketers (Yuktasir et al., 2004). Sport consumer may be dealt and handled as individuals who consume sportsrelated products and services with an overall perspective. Sport consumers can be classified under two main groups: Practitioners (active participants) and audience (passive participants). Passive participant can consume a sports event where it occurs (stadium, indoor sports hall, gymnasium etc.) as well as through mass media (newspaper, TV, radio etc.). Sports-related consumer behavior examines the decisions of sport consumers to purchase and use sports-related products, the activities related with these products and services and decision-making processes determining the activities related (Katirci and Argan, 2012). The field of consumer behaviors within the scope of the marketing management examines how individuals, groups and organizations choose products, services, opinions or experiences in order to satisfy their needs, requests and desires and how they purchase and use and dispose them (Kotler and Armstrong, 1989). Personality is the pattern of whole rooted behaviors, thoughts and feelings that emerge as the result of individual's social experiences, developments and structural features; it constitutes individual's mode of adaptation to his life style (Aksoy et al., 2011). The need to be informed and self-renewal throughout life leads people to diversify their areas of interest and exploration of new learning environments. Media is found in effective and impressive positions not as information source but in aspects of entertaining, educational and various ways since it can reach to everybody at various levels including both old and young people (Onal, 2007). One of the most important issues that may help people to analyze and have out the benefits of media is media literacy (Alagozlu, 2009). Media literacy can be defined as finding, using, accepting and determining written sources in order to develop the information and potential of students and allow them to participate in the community more effectively and make them contribute (Gunes and Gokcek, 2013). Media literacy has also other definitions although it expresses and means concepts such as analysis, synthesis, evaluation, implementation and production
(Blevins, 2004).

Media literacy is "the media exposure and interpretation of meanings of messages" according to Potter (2005). Media literacy has developed in United States of America since 1932 and in Austria, Belgium, France, Japan, England, Spain, Switzerland, Italy and Canada after the 1970s with developed skill courses (Onal, 2007). However, media literacy education has developed in the world after the 1970s (Mora, 2008). Development in media literacy took place in Turkey after the year 2004, although it has been very important especially in Western countries in the last thirty years (Altun, 2009). Media literacy can be defined as reaching, analyzing, evaluating and sending messages in written and unwritten, very large variety of formats (television, videos, movies, television commercials, advertisements, internet, etc.) (Rustu and Yesil, 2011; Manzo, 2007). Inceoglu (2006) defined media literacy as accessing, analyzing, evaluation and communication skills of people to messages in written and non-written formats (television, videos, movies, television commercials, advertisements, internet, etc.). Media literacy can be defined as reaching, analyzing, evaluating and sending messages in written and unwritten, very large variety of formats (Hobbs, 2004). Media literacy consists of two functions. The first one is the ability of individual to evaluate and filter messages received from the media with a critical perspective and the other is a concept including the ability of an individual to acquire recognize and use the media in a way to create his/her own individual messages (Pekman, 2006).

Individuals analyze the media consciously; express themselves easily and participate in social life actively and constructively. Due to media literacy, they perceive the media messages in a correct and accurate way and gain skills of creating their own messages in time (Korkmaz and Yesil, 2008).

Individuals' gained behaviors such as choosing appropriate TV programs in order to use television as an educational tool and information source, judging the time spent in front of television, using television based on personal reasons and being aware of ethical rules and complying with them have great importance (Yesil and Korkmaz, 2008).

This study aims to determine the media and television literacy levels and the addiction levels of sport consumers as well as to investigate and examine the relationship between these two levels.

\section{METHODS}

Research group includes sport consumers studying in the School of Physical Education and Sports in Mugla University. "Media and Television Literacy Levels Scale" developed by Korkmaz and Yesil (2011) was used in this study. Its validity and reliability was carried out by the researcher. The scale is composed of two dimensions: "literacy" including 13 items and "addiction" including 5 items. In the research, the margin of error was determined (alpha) $=0.005$, the tolerance level $(d)=0.05$, the number of persons included in the population $(N)=850$, and the sample size $(n)=409$. The 
researcher conducted 500 questionnaires by face-to-face interview on the students selected among the sport consumers. 409 questionnaire forms were determined valid and evaluated. Of the evaluated forms, 250 belonged to male students (77 from the department of Sport Management, 56 from the Physical Education and Sports Teaching, 78 from the Coaching Education and 39 from the Recreation) and 159 belonged to female students ( 45 from the department of Sport Management, 41 from the Physical Education and Sports Teaching, 44 from the Coaching Education and 29 from the Recreation).

Kaizer-Mayer-Oklin (KMO) and Bartlet test analyses were conducted to determine the construct validity. $\mathrm{KMO}$ was determined as 0.788 ; Bartlet test value $\times 2=813.003$ and the degree of freedom was 78 . Its suitability for factor analysis was tested in accordance with these figures. Internal consistency level was determined to set forth the reliability of the scale. Cronbach Alpha reliability coefficient was considered for determining internal consistency level. Media and television literacy levels were determined in accordance with the below-mentioned instruction. Correlation between the media and television addiction and the television literacy were examined. Considering the correlation coefficient, our data are not normally distributed; thus Spearman Correlation value was regarded. It was determined as -0.225 .

Media and Television Literacy Levels Scale is a five-point Likert type scale including 18 items under two factors. The answers to these items are as follows: (1) Never, (2) Rarely, (3) Sometimes, (4) Often, and (5) Always. Students' scores derived from the five-point Likert type scale are not standard due to the differences in item numbers of factors. Thus, the raw scores were changed into standard scores that are minimum 20 and maximum 100. The levels corresponding to the scores derived from the literacy dimension were determined as follows:

20-35: Very Low-Level Literacy

36-51: Low-Level Literacy

52-67: Medium-Level Literacy

68-83: High-Level Literacy

84-100: Very High-Level Literacy

The scores derived from the addiction dimension are also distributed similarly. However, literacy and addiction are inversely proportional. An individual with a high-level of literacy is likely to have a low-level of addiction. High addiction scores means an individual has a high-level of addiction and thus low-level of literacy (Yesil and Korkmaz, 2008). In data analysis, score intervals were determined as follows since students' responses to the five-point Likert type scale were used:

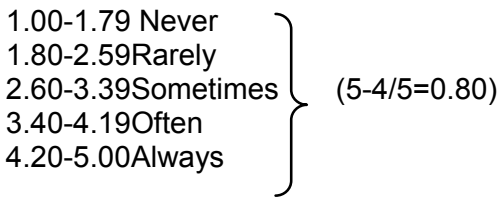

The average scores calculated based on the students' responses were explained in pursuant to the above-mentioned levels. Significance level was set at .05 for testing the significance of differences and correlations.

\section{FINDINGS}

Media and television literacy levels' Cronbach Alpha reliability coefficient was 0.73 and media and television addiction internal reliability was 0.75 .

$56.2 \%$ of participants answered often dimension (Table
1) of the media and television literacy questionnaire as "I know the characteristics of TV channels in our country and the factors determining their broadcasting policies". On the other hand, $0.5 \%$ of them answered (never) this dimension as "I know my TV watching habits and I can control them".

The mean value of media and television addiction level was determined as 2.08 . $70.9 \%$ of participants answered (never) dimension of addiction questionnaire as "I feel uncomfortable, unhappy or angry when I cannot watch TV". On the other hand, 3.2\% of them answered (always) this dimension as "I set back my social relations, education or other duties since I spare plenty of time for television" Table 2).

All average scores of distribution for media and television literacy levels are given in Table 3. As it seen, high average score was the answer of "I know the meanings of smart signs showing the suitability of TV programs for children or adults that are displayed just before the programs".

Male and female Sports Consumers' media and television addiction levels were found as $X^{-}=2,08$. Furthermore, all participants' media and television addiction levels were lower level (Table 4).

There was no statistically significant difference in media and television literacy levels between male and female sports consumers. Moreover, all participants had higher degree in media and television literacy levels $\left(X^{-}=4.01\right)$ (Table 5).

Table 6 shows that there was no significant difference in media and television literacy levels between departments of School of Physical Education and Sports and gender.

There was no significant difference in media and television addiction levels between departments of School of Physical Education and Sports and gender (Table 7).

There was a negative correlation between media and television literacy and addiction levels of sport consumers $(p<0,05)$. Spearman correlation value was determined as -0.225 (Table 8).

\section{DISCUSSION AND CONCLUSION}

This study was conducted to determine the media and television literacy and addiction levels of sport consumers who are students of the School of Physical Education and Sports and to research the relationship between these levels. $39.9 \%$ of students were found to be literate, $49.6 \%$ to be high-level media and television literate and $10.5 \%$ were found to be medium-level media and television literate. According to this table, media and television literacy levels of sport consumers can be said to be extremely high.

Potter (2005) describes media literacy as a series of viewpoints or perspectives used to interpret the meanings of messages encountered. According to this result, sport 
Table 1. Distribution of answers given to the media and television literacy dimension.

\begin{tabular}{|c|c|c|c|c|c|}
\hline \multirow{2}{*}{ Literacy } & \multirow{2}{*}{$\begin{array}{c}\text { Never } \\
\text { Row N \% }\end{array}$} & \multirow{2}{*}{$\begin{array}{c}\text { Rarely } \\
\text { Row N \% } \\
\end{array}$} & \multirow{2}{*}{$\begin{array}{c}\text { Sometimes } \\
\text { Row N \% }\end{array}$} & \multirow{2}{*}{$\begin{array}{c}\text { Often } \\
\text { Row N \% }\end{array}$} & \multirow{2}{*}{$\begin{array}{c}\text { Always } \\
\text { Row N \% }\end{array}$} \\
\hline & & & & & \\
\hline $\begin{array}{l}\text { I think media works for the benefit of some people and excludes } \\
\text { some others. }\end{array}$ & $.5 \%$ & $4.4 \%$ & $21.5 \%$ & $43.8 \%$ & $29.8 \%$ \\
\hline $\begin{array}{l}\text { I know the intended and resultant effects of the techniques used in } \\
\text { media for creating emotional influences. }\end{array}$ & $0.0 \%$ & $1.7 \%$ & $11.7 \%$ & $56.2 \%$ & $30.3 \%$ \\
\hline $\begin{array}{l}\text { I know the characteristics of TV channels in our country and the } \\
\text { factors determining their broadcasting policies. }\end{array}$ & $.2 \%$ & $2.4 \%$ & $16.6 \%$ & $50.6 \%$ & $30.1 \%$ \\
\hline $\begin{array}{l}\text { I think special techniques are used in media for creating emotional } \\
\text { influences. }\end{array}$ & $.2 \%$ & $4.6 \%$ & $12.5 \%$ & $37.4 \%$ & $45.2 \%$ \\
\hline $\begin{array}{l}\text { I can distinguish TV shows by their objectives, functions and } \\
\text { characteristics. }\end{array}$ & $2.0 \%$ & $4.2 \%$ & $12.0 \%$ & $34.5 \%$ & $47.4 \%$ \\
\hline I question who benefit from the media and who is excluded and why. & $3.4 \%$ & $17.4 \%$ & $35.2 \%$ & $26.7 \%$ & $17.4 \%$ \\
\hline $\begin{array}{l}\text { I think the opinions, information and news in media are broadcasted } \\
\text { from someone else's point of view. }\end{array}$ & $.7 \%$ & $4.9 \%$ & $21.0 \%$ & $46.5 \%$ & $26.9 \%$ \\
\hline $\begin{array}{l}\text { I know the meanings of smart signs showing the suitability of TV } \\
\text { programs for children or adults that are displayed just before the } \\
\text { programs. }\end{array}$ & $1.2 \%$ & $6.1 \%$ & $10.5 \%$ & $20.5 \%$ & $61.6 \%$ \\
\hline $\begin{array}{l}\text { I examined and evaluated the TV programs by content, reality, } \\
\text { fictiveness, consumption targeting and misinformation. }\end{array}$ & $2.7 \%$ & $15.6 \%$ & $31.3 \%$ & $34.0 \%$ & $16.4 \%$ \\
\hline $\begin{array}{l}\text { I think television is an effective media in shaping individuals and } \\
\text { society. }\end{array}$ & $1.5 \%$ & $3.2 \%$ & $10.3 \%$ & $30.8 \%$ & $54.3 \%$ \\
\hline $\begin{array}{l}\text { I search for and use other sources of information and amusement } \\
\text { alternative to the media. }\end{array}$ & $.7 \%$ & $3.9 \%$ & $14.4 \%$ & $38.1 \%$ & $42.8 \%$ \\
\hline I know my TV watching habits and I can control them. & $.5 \%$ & $3.9 \%$ & $12.2 \%$ & $43.3 \%$ & $40.1 \%$ \\
\hline $\begin{array}{l}\text { I define the potential problems of TV broadcasts and take measures } \\
\text { to get protected from them. }\end{array}$ & $2.0 \%$ & $7.3 \%$ & $27.9 \%$ & $41.1 \%$ & $21.8 \%$ \\
\hline
\end{tabular}

Table 2. Distribution of answers given to the media and television addiction dimension.

\begin{tabular}{|c|c|c|c|c|c|}
\hline \multirow{2}{*}{ Addiction } & Never & Rarely & Sometimes & Often & Always \\
\hline & Row N \% & Row N \% & Row N \% & Row N \% & Row N \% \\
\hline $\begin{array}{l}\text { I set back my social relations, education or other duties since I spare } \\
\text { plenty of time for television. }\end{array}$ & $54.3 \%$ & $25.9 \%$ & $11.2 \%$ & $5.4 \%$ & $3.2 \%$ \\
\hline $\begin{array}{l}\text { I use television for evading issues or for suppressing depression, } \\
\text { anxiety, responsibility or desperation. }\end{array}$ & $20.5 \%$ & $30.8 \%$ & $25.2 \%$ & $16.9 \%$ & $6.6 \%$ \\
\hline I look forward to watch TV when I think of TV programs. & $27.4 \%$ & $30.8 \%$ & $25.9 \%$ & $12.0 \%$ & $3.9 \%$ \\
\hline I feel uncomfortable, unhappy or angry when I cannot watch TV. & $70.9 \%$ & $16.1 \%$ & $7.6 \%$ & $4.9 \%$ & $.5 \%$ \\
\hline I spend much more time watching TV than I intended. & $30.1 \%$ & $28.1 \%$ & $31.1 \%$ & $7.8 \%$ & $2.9 \%$ \\
\hline
\end{tabular}

consumers in our sample group can be said to have a perspective focus on the definition of media literacy and skill of creating personal meaning. Today, while information technologies lead to social transformation, media literacy emerges as an important life skill in terms of people to be aware of factors affecting themselves, other communities and cultures (Deveci and Cengelci, 2008). Due to the fact that these skills of sport consumers have been known less, a marketing effort towards themselves has a great importance.

We can say that there is an inverse relationship between the scores of media and television literacy levels (literacy and addiction) of the participants as a result of the examination in two sections. The average literacy level of students was found at high level $\left(X^{-}=4.01\right)$ and the addiction level of them was found at low level ( $X^{-}$ =2.08). A negative relationship was found between literacy and addiction considering the relationship between them $(p<0.05)$. Average literacy levels of consumers were found at high-level and addiction levels at low-level. The scores derived from the addiction dimension are also distributed similarly. However, literacy and addiction are inversely proportional. An individual with a high-level of literacy is likely to have a low-level of addiction. High 
Table 3. Average score distribution for media and television literacy levels.

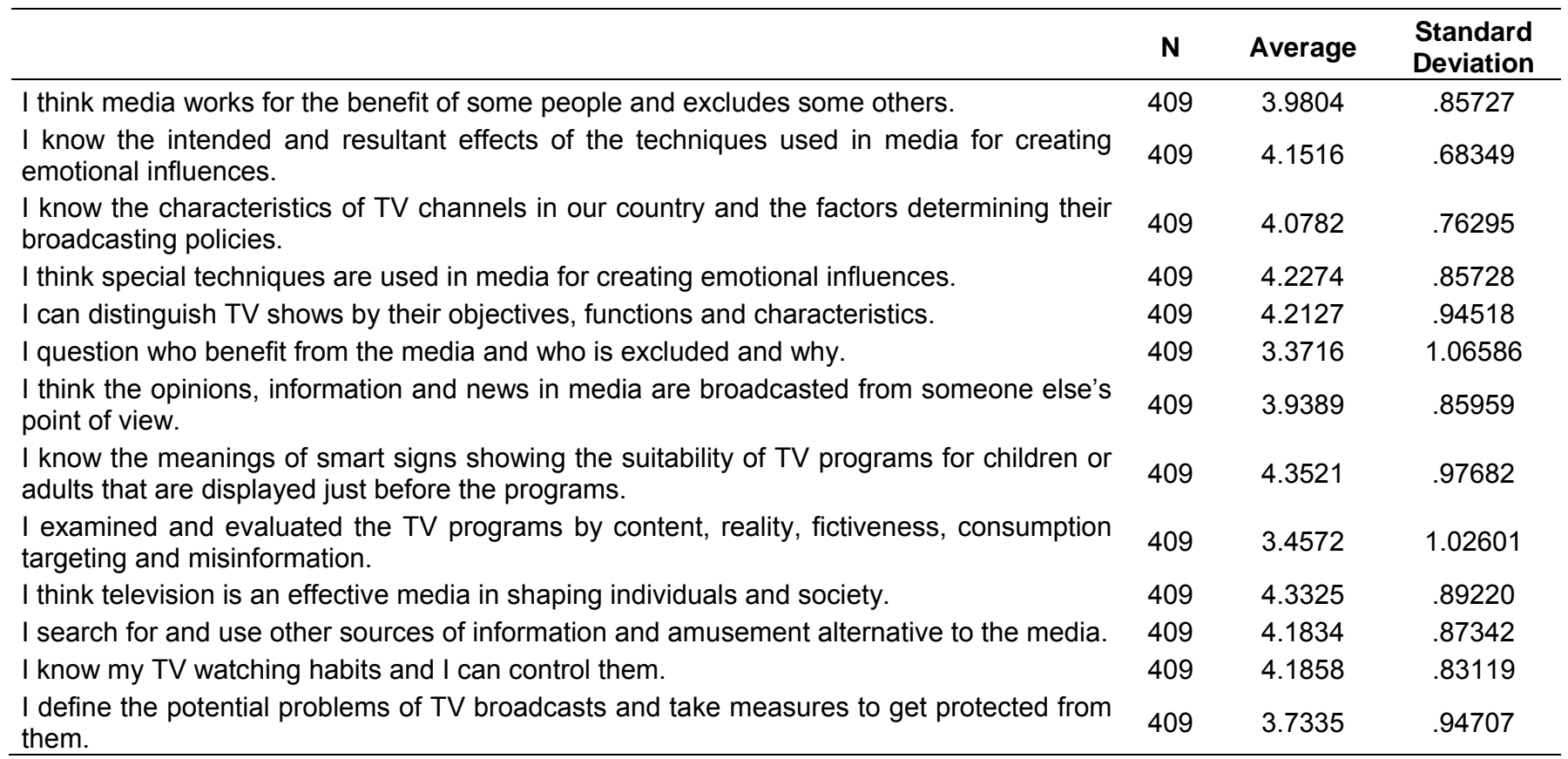

Table 4. Average score distribution for media and television addiction levels.

\begin{tabular}{|c|c|c|c|}
\hline & $\mathbf{N}$ & Average & $\begin{array}{l}\text { Standard } \\
\text { deviation }\end{array}$ \\
\hline I set back my social relations, education or other duties since I spare plenty of time to television. & 409 & 1.7726 & 1.05237 \\
\hline $\begin{array}{l}\text { I use television for evading the issues or for suppressing depression, anxiety, responsibility or } \\
\text { desperation. }\end{array}$ & 409 & 2.5819 & 1.17938 \\
\hline I look forward to watch TV when I think of the TV programs. & 409 & 2.3423 & 1.11812 \\
\hline I feel uncomfortable, unhappy or angry when I cannot watch TV. & 409 & 1.4792 & .86895 \\
\hline I spend much more time watching TV than I intended. & 409 & 2.2543 & 1.06130 \\
\hline
\end{tabular}

addiction scores means an individual has a high-level of addiction and thus low-level of literacy (Yesil and Korkmaz, 2008).

The study titled "Opinions of teacher candidates on television addiction, literacy levels and instructiveness" conducted by Yesil and Korkmaz (2008) shows so close similarity with our study conducted about the relationship between media addiction and television addiction and media literacy and television literacy.

Increasing and improving role of television in social life as the most popular and common mass communication media tool lead to the results of this effect to be questioned. The average of watching television for our country is 4 to 5 hours per day according to the scientific research conducted in Turkey. A single person spends $19 \%$ of the year by watching television. Taking into account that a single person spends $33 \%$ of the year by sleeping and $33 \%$ of the year by working and $14 \%$ by activities out of the first two, that rate has been considered to be quite high. This situation means that the time remaining for vital activities is consumed by watching television (Altun, 2009). In addition, it is inevitable that internet literacy will bring many problems along with it while internet shows its rapid and quick impact in many areas.

Media may distort, twist, exaggerate and hide the facts and even changes the form of the facts in order to create more market share, direct political powers and increase advertising revenues. Everything you see in the media may not be an exact reflection of the reality (Sahin and Tuzel, 2011). No matter how much the media has constructed its messages ruthlessly and aggressively, individuals who have reached the level of cognitive awareness in the issue of media will be able to have the competence to analyze and process the backgrounds of these messages (Sahin and Tuzel, 2011). Sport 
Table 5. Distribution of scores of the male and female concerning media and television literacy levels.

\begin{tabular}{|c|c|c|c|c|c|c|c|c|c|c|c|c|c|}
\hline & \multicolumn{10}{|c|}{ Literacy Level } & \multirow{3}{*}{$\mathbf{N}$} & \multirow{3}{*}{ Chi-square } & \multirow{3}{*}{$p$ value } \\
\hline & \multicolumn{2}{|c|}{ Illiterate } & \multicolumn{2}{|c|}{ Low-Level } & \multicolumn{2}{|c|}{ Medium-Level } & \multicolumn{2}{|c|}{ High-Level } & \multicolumn{2}{|c|}{ Literate } & & & \\
\hline & $\mathbf{F}$ & $\%$ & $\mathbf{F}$ & $\%$ & $\mathbf{F}$ & $\%$ & $\mathbf{F}$ & $\%$ & $\mathbf{F}$ & $\%$ & & & \\
\hline Female & 0 & $0.0 \%$ & 0 & $0.0 \%$ & 12 & $7.5 \%$ & 79 & $49.7 \%$ & 68 & $42.8 \%$ & 159 & 27 & (2) \\
\hline Male & 0 & $0.0 \%$ & 0 & $0.0 \%$ & 31 & $12.4 \%$ & 124 & $49.6 \%$ & 95 & $38.0 \%$ & 250 & 2.13 & $0, \angle 0$ \\
\hline
\end{tabular}

Table 6. Distribution of scores of the male and female concerning media and television literacy levels according to participants' departments.

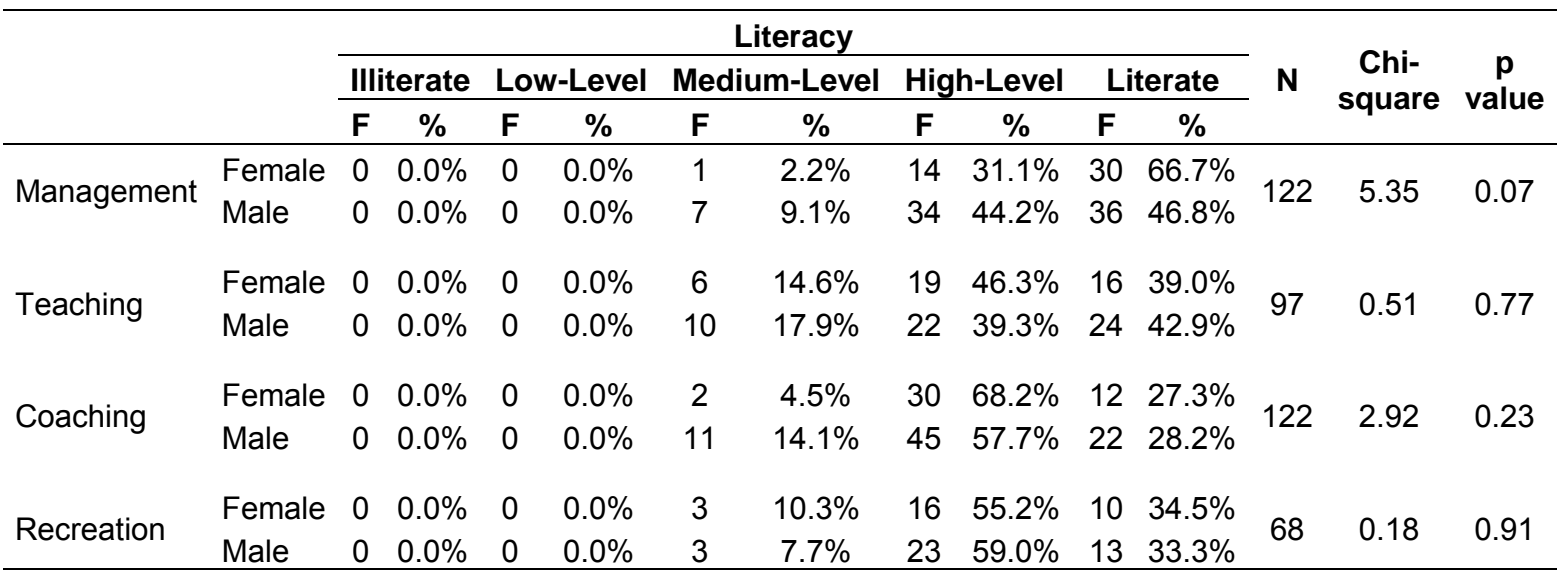

Table 7. Distribution of scores of the male and female concerning media and television addiction.

\begin{tabular}{|c|c|c|c|c|c|c|c|c|c|c|c|c|c|c|}
\hline & & \multicolumn{10}{|c|}{ Addiction } & \multirow{3}{*}{$\mathbf{N}$} & \multirow{3}{*}{$\begin{array}{c}\text { Chi- } \\
\text { square }\end{array}$} & \multirow{3}{*}{$\begin{array}{c}\mathbf{p} \\
\text { value }\end{array}$} \\
\hline & & \multicolumn{2}{|c|}{ Highly non-addicted } & \multicolumn{2}{|c|}{ Non-addicted } & \multicolumn{2}{|c|}{ Neutral } & \multicolumn{2}{|c|}{ Addicted } & \multicolumn{2}{|c|}{ Highly addicted } & & & \\
\hline & & $\mathbf{F}$ & $\%$ & $\mathbf{F}$ & $\%$ & $\mathbf{F}$ & $\%$ & $\mathbf{F}$ & $\%$ & $\mathbf{F}$ & $\%$ & & & \\
\hline Management & Male & 41 & $53.2 \%$ & 29 & $37.7 \%$ & 5 & $6.5 \%$ & 2 & $2.6 \%$ & 0 & $0.0 \%$ & 122 & 3.07 & 0.38 \\
\hline Teaching & Female & 21 & $51.2 \%$ & 16 & $39.0 \%$ & 2 & $4.9 \%$ & 2 & $4.9 \%$ & 0 & $0.0 \%$ & 97 & 4.36 & 0.36 \\
\hline \multirow{2}{*}{ Coaching } & Female & 13 & $29.5 \%$ & 22 & $50.0 \%$ & 4 & $9.1 \%$ & 4 & $9.1 \%$ & 1 & $2.3 \%$ & \multirow{2}{*}{122} & \multirow{2}{*}{8.50} & \multirow{2}{*}{0.07} \\
\hline & Male & 33 & $42.3 \%$ & 23 & $29.5 \%$ & 16 & $20.5 \%$ & 6 & $7.7 \%$ & 0 & $0.0 \%$ & & & \\
\hline \multirow{2}{*}{ Recreation } & Female & 10 & $34.5 \%$ & 12 & $41.4 \%$ & 7 & $24.1 \%$ & 0 & $0.0 \%$ & 0 & $0.0 \%$ & \multirow{2}{*}{68} & \multirow{2}{*}{3.78} & \multirow{2}{*}{0.44} \\
\hline & Male & 14 & $35.9 \%$ & 10 & $25.6 \%$ & 12 & $30.8 \%$ & 2 & $5.1 \%$ & 1 & $2.6 \%$ & & & \\
\hline
\end{tabular}

consumers who are effective read and evaluate the media in a conscious way. Although a consumer is a conscious media literate, s/he may be affected through the mass media negatively. Mass media tools that are supposed to provide solutions to violence in sports and educate and direct the audience lead to a number of ethical problems by ignoring public broadcasting and acting only to get more profit and income (Karagun, 2011).

Ilhan and Zafer (2011) expressed as a result of their studies that $76.2 \%$ of sports columnists have an opinion that sport media is effective in encouraging and inciting violence and $11.9 \%$ of them think that media has not got any kind of effect in this issue and $57.1 \%$ of the participants have an opinion that media is accused of encouraging and inciting violence because it reflects the statements or explanations of club managers to readers and viewers directly.

From past to present, both sports have influence on 
Table 8. Distribution of correlation between the media and television literacy and addiction of participants

\begin{tabular}{|c|c|c|c|c|c|c|c|}
\hline & & \multicolumn{5}{|c|}{ Addiction Interval } & \multirow{2}{*}{ Total } \\
\hline & & Highly non-addicted & Non-addicted & Neutral & Addicted & Highly addicted & \\
\hline & Medium-Level & 16 & 8 & 18 & 1 & 0 & 43 \\
\hline \multirow[t]{2}{*}{ Literacy Level } & High-Level & 80 & 78 & 29 & 13 & 3 & 203 \\
\hline & Literate & 92 & 57 & 11 & 3 & 0 & 163 \\
\hline Total & & 188 & 143 & 58 & 17 & 3 & 409 \\
\hline
\end{tabular}

media as well as the media on sports. Especially, the mass media has a great role in that position where sports have become a social phenomenon all over the world and at the same time, the majority who have no opportunity to do sports, have become interested in sports due to the mass media (Ozturk, 1998; Unsal and Ramazanoglu, 2013). Fedorov (2003) found as a result of his study conducted on 26 media literacy and media training specialists from 10 different countries in order to learn what the aim and purpose of media literacy is in their opinions that $84.2 \%$ of the specialists described and characterized media literacy as developing critical thinking skills of individuals, $68.8 \%$ as developing individuals' skills of understanding and evaluating media statements and $61.8 \%$ as preparing individual to create a democratic society. Increasing media and television literacy levels of especially sport consumers and society have importance in order to increase sports awareness. Kincal (2007) states as a result of his study that teacher candidates submit their reactions or criticisms about positive or negative messages in the media to the relevant institutions at a very low level and remain indifferent and unconcerned against the media in general (Kincal, 2007). Sports-oriented publications with negative content create so much information pollution in the media. Increasing awareness of sport consumers to response official institutions against negativities in the media about especially sports-related issues will contribute to the formation of conscious consumers. As a result of the study titled "Research of community attitudes in the issue of effect of community leaders and the media on dissemination and generalization of sports" that was conducted by Unal et al. (2009), it was found that sports media cannot raise the awareness of community and public adequately and expectations from the media, community leaders, government and private sector are high in this issue (Unal, 2009). Sports media that can contribute greatly to the formation of sports to be a very common social phenomenon to be inflated with simple, fluctuating and marginalizing news by cutting corners is a very big and major social loss (Yetim, 2005). Efforts which will carry much more information and skills about media analysis and production to a wider variety and diversity of media by reaching much more educators, children and young people through well-organized programs, activities and educational experiences are required (Hobbs, 2004). Nowadays, responsibilities in the issue of transformation and converting the society into healthy, livable, reliable and safe environments are being shared. Media literacy integrating with information sources and services from past to the future, will provide a hopeful look for the future by teaching "all of us" the accurate, conscious, efficient and effective use of information and knowing what we are looking for in life and the future (Onal, 2007).

Consequently, sport consumers selected from the students of the School of Physical Education and Sports were found to have high media television literacy levels; and it has also been found that there is an inverse relationship between their media and television literacy and addiction and their average literacy level is at highlevel and addiction level is at low-level.

\section{Conflict of Interests}

The author has not declared any conflict of interest.

\section{REFERENCES}

Aksoy MU, Kırımoğlu H, Aksoy ŞG (2011). Affective temperaments in the students of the School of Phyisical Education and Sports. Educ. Res. Rev. 6(23):1058-1062.

Alagozlu C (2009). Media literacy in Turkey and the European Union. Radio and Television Supreme Council Dissertation pp.5-15.

Altun A (2009) A critical approach to elective media literacy curriculum in terms of pedagogy. J. Faculty Educ. Ahi Evran University 10(3):97109.

Blevins M (2004). Information and media literacy education within the school library media centers of a middle Tennessee county. phd. Dissertation, Tennessee State University.

Deveci H, Cengelci T (2008). An overview of social studies teacher candidates to media literacy, J. Faculty Educ. Yuzuncu Yil University $5(2): 25-43$.

Fedorov A (2003). Media education and media literacy: experts' opinions. In: mentor. A media education curriculum for teachers in the Mediterranean. Paris: UNESCO.

Gençer RT (2001). Sport marketing strategies of national sports federations. Unpublished Master's Thesis, Institute of Health Sciences, E.U.

Goknar H (2001). Interpersonal communication and mass communication in marketing; an application on the detergent industry in Kayseri. Unpublished Master's Thesis; Erciyes University, Institute of Social Sciences.

Gunes G, Gokcek T (2013). Determination of mathematics literacy levels of teacher candidates. Dicle University, Ziya Gokalp J. Faculty Educ. 20:70-79. 
Hobbs $R$ (2004). Seven great debates in the media literacy movement. (Translation: Melike Türkan Bagli), Ankara University, J. Faculty Educ. Sci. 37(1):122-140.

Inceoglu $Y$ (2006). Learning media in the right manner. First International Media Literacy Conference. Marmara University, Conference Papers of Faculty of Communication.

Ilhan C, Cimen Z (2011). The effects of violence and sport media in the field of sports: Perceptions of sports columnists. Nigde University, J. Phys. Educ. Sports Sci. 5(3):224-234.

Karagun E (2011). Violence and sports, Turkey Clinics, J. PsychiatrySpecial Topics 4(2):79-85

Katirci H, Argan M (2012). Sports Marketing. Anadolu University Publications. 2481(1):35-55.

Kincal RY (2007). Media literacy as a means of perceiving globalization. ISA RC 47 Social classes and social movementsglobalization, conflicts and experiences of localities, University of Rome.

Korkmaz O, Yesil R (2011). Validity and reliability study of the Media and Television Literacy Level Scale. J. Int. Human Sci. 8(2):111-126.

Kotler P, Gary A (1989). Principles of Marketing, Prentice Hall Englewood Cliffs. New Jersey p.171.

Manzo KK (2007). Alliance provides 'core principles' for media literacy. Education Week.

Mora N (2008). Media Studies: Media Pedagogy and Global Communication. Alt Kitap p.71.

Onal HI (2007). Media literacy: A new field of study in libraries. Turkish Librarianship 21(3):335-359.

Ozturk F (1998). Sports with Social Aspects. Ankara: Bagirgan Publications.

Pekman C (2006). Media literacy in the European Union. First International Media Literacy Conference. Marmara University, Conference Papers of Faculty of Communication.

Potter WJ (2005). Media Literacy. Sage Publications (Third Edition), California pp.23- 28
Sahin C, Tuzel S (2011). Determination of media world's reflection level of real world in accordance with the opinions of teacher candidates. Educ. Sci. 36(159):127-140.

Terence AS (1989). Promotion Management and Marketing Communication, The Dreyden Press p.175.

Unal H (2009). Effect and influence of social marketing on promotion and generalization of sport awareness. Marmara University, Institute of Health Sciences, Department of Physical Education and Sports, Dissertation.

Unal H, Agilonu A, Geri S (2009). Research on attitudes of community in the matter of effect of community leaders and media, International Congress of Sport for all and Sport Tourism.

Unsal B, Ramazanoglu F (2013). Sociological effect of sports media on society. J. Educ. Teach Res. 2(1).

Yalcin HB, Yuktasir B, Dogru Z (2004). Marketing components in sport consumption. Hacettepe J. Sport Sci. 15(4):1219-232.

Yalcin HB, Yuktasir B, Dogru Z (2004). Differences in sport consumers and sports marketing components. Ataturk University, J. Phys. Education and Sport Sciences. 6(2):35-44.

Yetim A (2005). Sociology and Sports, Morpa Culture Publications. 131209.

Yesil R, Korkmaz O (2008). Opinions of teacher candidates on television addiction, literacy levels and instructiveness. Selcuk University, Ahmet Kelesoglu J. Faculty Educ. (26):55-72. 